\title{
The Flying Laboratory for the Observation of ADS-B Signals
}

\author{
Raymond Francis, ${ }^{1}$ Ronald Vincent, ${ }^{2}$ Jean-Marc Noël, ${ }^{2}$ Pascal Tremblay, ${ }^{3}$ Daniel Desjardins, ${ }^{4}$ \\ Alex Cushley, ${ }^{2}$ and Matthew Wallace ${ }^{4}$ \\ ${ }^{1}$ Department of Electrical and Computer Engineering, The University of Western ON, 1151 Richmond Street, Suite 2, London, ON, \\ Canada N6A $5 B 8$ \\ ${ }^{2}$ Department of Physics, Royal Military College of Canada, P.O. Box 17000, Station Forces Kingston, ON, Canada K7K 7B4 \\ ${ }^{3}$ Defence R\&D Canada-Ottawa, 3701 Carling Avenue, Ottawa, ON, Canada K1A 0Z4 \\ ${ }^{4} 15$ Wing, P.O. Box 5000, Moose Jaw, SK, Canada S6H $7 Z 8$
}

Correspondence should be addressed to Ronald Vincent, ron.vincent@rmc.ca

Received 14 June 2011; Accepted 22 August 2011

Academic Editor: Gyu-In Jee

Copyright (C) 2011 Raymond Francis et al. This is an open access article distributed under the Creative Commons Attribution License, which permits unrestricted use, distribution, and reproduction in any medium, provided the original work is properly cited.

\begin{abstract}
Automatic dependent surveillance-broadcast (ADS-B) is a system in which aircraft continually transmit their identity and GPSderived navigational information. ADS-B networks for air traffic monitoring have already been implemented in areas around the world, but ground stations cannot be installed in midocean and are difficult to maintain in the Arctic, leaving a coverage gap for oceanic and high latitude airspace. A potential solution for worldwide tracking of aircraft is through the monitoring of aircrafttransmitted ADS-B signals using satellite-borne receivers. To investigate this possibility, a high altitude balloon experiment was carried out in June 2009 to determine if ADS-B signals can be detected from near space. The Flying Laboratory for the Observation of ADS-B Transmissions (FLOAT) was the first stratospheric platform to collect ADS-B data. The FLOAT mission successfully demonstrated the reception of ADS-B signals from near space, paving the way to the development of a space-based ADS-B system.
\end{abstract}

\section{Introduction}

Current radar surveillance cannot track aircraft beyond sight of land, requiring traffic over the ocean to use inefficient and imprecise procedural techniques to provide separation. Provision of continuous surveillance in this airspace would increase safety and security of air traffic, as well as allowing aircraft to follow more direct routes, saving time and fuel while reducing engine emissions. Such a system could also be used over land, for example, in Canada's high arctic, where large areas are without air traffic surveillance.

An alternate method of providing aircraft position data is by automatic dependent surveillance-broadcast (ADS-B), in which aircraft continually transmit their identity and navigational information. ADS-B signals are received by ground stations and relayed to Air Traffic Services (ATSs) where they are used to supplement radar data. These transmissions can also be received by other aircraft to allow aircrews knowledge of nearby traffic. ADS-B has the advantage that the ground stations are less complex and have lower power requirements than radar installations, so ADS-B stations can be installed in remote areas for lower cost [1]. ADS-B networks have already been implemented in areas around the world, but ground stations cannot be installed in midocean and are difficult to build and maintain in the Arctic, leaving a coverage gap for oceanic and high latitude airspace.

A potential solution for the accurate surveillance and tracking of aircraft anywhere in the world is through the monitoring of aircraft-transmitted ADS-B signals using satellite-borne receivers. To investigate this possibility, an experiment was undertaken by the Royal Military College of Canada (RMCC) to determine if ADS-B signals can be detected from near space. This paper describes the experimental procedure and results of the Flying Laboratory for the Observation of ADS-B Transmissions (FLOAT). The data collected by the FLOAT payload represents the first-ever collection of ADS-B data from a stratospheric balloon platform. 


\section{ADS-B Signal}

The ADS-B signal contains global positioning system (GPS) positional data, as well as aircraft identification and velocity. There are currently three types of ADS-B transmissions, including the $1090 \mathrm{MHz}$ extended squitter (ES), the $978 \mathrm{MHz}$ universal access transceiver (UAT), and the VHF data link (VDL) mode 4 operating between 108 and $137 \mathrm{MHz}$. Canada's implementation of ADS-B surveillance in Canadian airspace, notably over the Hudson Bay region since January 2009, uses the $1090 \mathrm{MHz}$ ES [2, 3]. This same system is also being adopted by ATS organizations in both the United States and Europe $[4,5]$. While smaller aircraft may use UAT and VDL, the ES $1090 \mathrm{MHz}$ signal is expected to be adopted for global use. Larger aircraft are required to have $1090 \mathrm{MHz}$ mode $S$ transponder equipment for collision avoidance, so the use of the ES carrier for ADS-B is the most cost-effective path.

The ES ADS-B message is a 120 bit transmission that contains the aircraft identification, position, velocity, and status. The message is broadcast with a period that ranges randomly between 0.4 and 0.6 seconds. This randomization function is designed to prevent aircraft from having synchronized transmissions on the same frequency, and thus obscuring each other's transmissions. Required transmitter power for the ADS-B signal varies with the aircraft category. For smaller aircraft, a minimum transmission power of $75 \mathrm{~W}$ is specified while larger aircraft require a minimum power of $125 \mathrm{~W}$ or $200 \mathrm{~W}$ with a maximum output power for all classes of $500 \mathrm{~W}$ [6]. Any aircraft that is capable of operating at altitudes greater than $15,000 \mathrm{ft}(4570 \mathrm{~m})$ above sea level (ASL), or with cruising speeds above $175 \mathrm{kts}(324 \mathrm{~km} / \mathrm{h})$, are required to transmit at $125 \mathrm{~W}$ as a minimum [6]. Aircraft use a quarter-wave monopole antenna for ADS-B transmissions that transmit vertically polarized signals [6].

\section{FLOAT Experiment}

The FLOAT system carried a receive-only ADS-B detector, capable of receiving and recording signals from aircraft using the $1090 \mathrm{MHz}$ ES. The system was carried by a selfbursting stratospheric sounding balloon, capable of reaching altitudes higher than $90,000 \mathrm{ft}(27,432 \mathrm{~m})$ ASL. Airline traffic commonly cruises at altitudes from 29,000 to $43,000 \mathrm{ft}$ ASL [7], so the goal was to detect ADS-B signals above these altitudes. For redundancy, observed ADS-B data was recorded onboard for later recovery and transmitted by radio to a ground station at the launch site. The system was designed as a lightweight payload to allow its accommodation on a sounding balloon of the type used by meteorological agencies for daily upper air monitoring. The total payload mass was $3.0 \mathrm{~kg}$, with no requirement for system attitude control or pointing.

The FLOAT payload system consisted of an insulated canister containing the sensor systems and supporting hardware. It was designed with a ten-hour operational lifetime, sufficient for preflight checks, launch process, flight operations, and estimated recovery time, with a two-hour

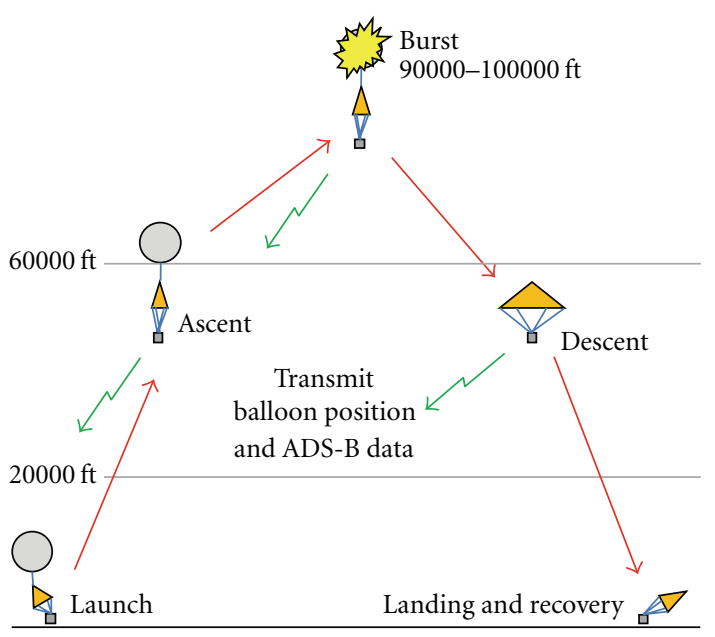

FIGURE 1: FLOAT mission profile [9].

margin. The primary sensor was a commercial ADS-B detector and antenna. Position and tracking data were provided by a space-qualified GPS receiver, so there was no restriction on the altitude for determining positional information. A thermocouple was also included to sense internal and external temperature during the mission. This temperature information was intended for later technical analysis and potential fault diagnosis, but it also served to provide a sounding of the atmospheric temperature profile.

The operations of the sensor subsystems were supported by an onboard computer. Data was stored both on the computer hard disk and a solid-state storage device. Additionally, a UHF radio was used to send the data to the ground station as it was recorded. These support subsystems, and the sensor elements were powered by a system of batteries and a power regulation unit. All of the components were housed together in a payload canister for protection against the elements during the mission. The canister was built of rigid insulating polymer foam faced with aluminum foil and sealed with aluminum tape. It was designed to insulate the payload components from potential stratospheric temperatures of $-56^{\circ} \mathrm{C}[8]$, to protect the internal components from the force of impact during landing, and to be buoyant and leak resistant in case of a water landing. Aside from the radar-reflective external layer, the key external features of the canister were the housing for a secondary commercial GPS tracking system, the antennas for the ADS-B and GPS receivers and telemetry radio, and the external portion of the thermocouple wire of the temperature sensor. The canister also carried markings identifying the payload and its launching authority, as required by the relevant regulations, and, to aid in the recovery of the payload in the event the retrieval team was unable to locate it. The mission profile for the FLOAT experiment is shown in Figure 1, while Figure 2 shows the FLOAT system shortly after launch.

The first FLOAT mission experienced computer problems early in the flight and returned limited data, however, a second mission (FLOAT-2) was successfully launched three weeks later on 12 June 2009 from Wingham, Ontario. 


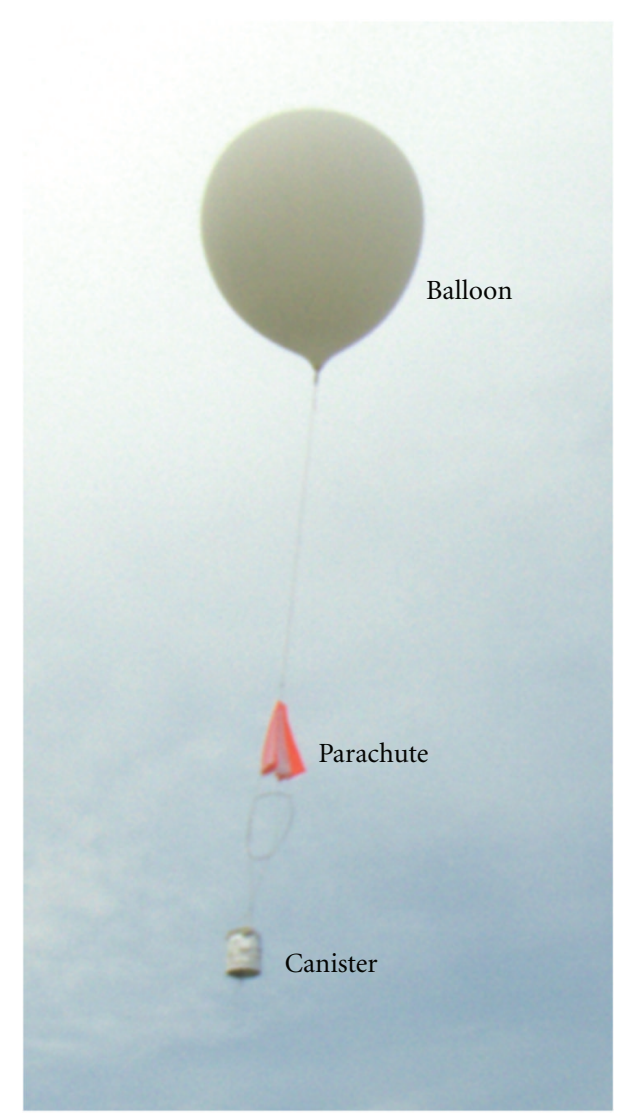

FIgURE 2: FLOAT launch from Wingham, ON, Canada.

Following an ascent to $92,850 \mathrm{ft}$ ASL $(28.3 \mathrm{~km})$, the FLOAT-2 payload descended by parachute and came to rest in a tree $90 \mathrm{~km}$ east of the launch site after a flight of 2.4 hours. The average ascent rate of FLOAT-2 was $4.2 \mathrm{~m} / \mathrm{s}$, while the descent rate averaged $13.7 \mathrm{~m} / \mathrm{s}$. Telemetry was unreliable during the late phases of the flight, but the secondary tracking system allowed recovery of the payload. Shortly after recovery, it was ascertained that a complete data set had been recorded by the payload, with ADS-B, GPS, and temperature data as planned. All hardware survived the flight, with the exception of the ADS-B antenna, which was torn from its mount during the landing. The dataset was archived for later analysis at RMCC, bringing the FLOAT program to a successful conclusion.

\section{FLOAT Data Analysis}

FLOAT-2 successfully observed ADS-B transmissions from aircraft, meeting the mission's primary science goal. During the 2.4 hour flight, a total of 2,076 individual messages were received from aircraft. The ADS-B data was logged by the commercial software associated with the ADS-B receiver in separate files at intervals of one minute. In the event that no messages were detected in the corresponding one minute period, no file was created. Notably, there was a period of reduced data recording, spanning 13.6 minutes during the payload's descent by parachute. During this time, only two ADS-B messages were detected, significantly less than the

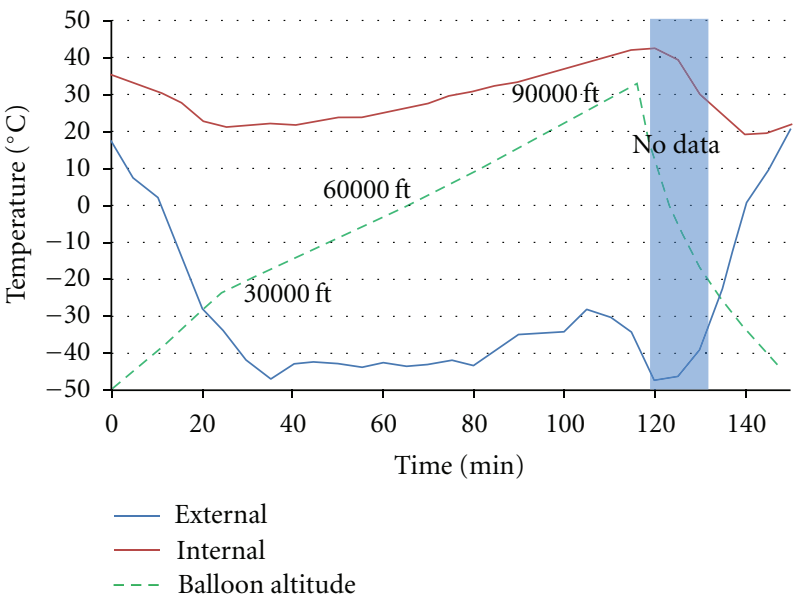

Figure 3: Internal and external temperatures for FLOAT-2 in relation to signal gap and balloon altitude. The internal and external temperatures are averaged in five-minute increments. The dashed line represents the altitude profile, while the shaded area shows the period of reduced signal reception.

average of 15.8 per minute for the remainder of the flight. This interruption of the recording is thought to have been the result of the cold external temperatures $\left(-29.3\right.$ to $\left.-50.9^{\circ} \mathrm{C}\right)$ experienced during this timeframe. The antenna provided with the commercial ADS-B receiver was a full-wavelength monopole connected to the antenna mount by a threaded plastic fastener that butts the end of the antenna against the antenna lead. It is possible that the thermal contraction of the antenna and the lead caused these elements to lose contact with each other at the butt joint. In that event, the conduction of received signals from the antenna to the lead could become unreliable, though perhaps not consistently or completely interrupted, particularly as the components begin to warm. Such behaviour of the antenna becoming isolated from the lead in cold temperatures could explain the observed signal gap. Jostling of the antenna due to the rapid descent rate may have also contributed to reduced signal reception. Figure 3 shows internal and external temperatures for FLOAT-2 in relation to the signal gap and payload altitude.

The portion of the flight in which the balloon was above an altitude of $60,000 \mathrm{ft}(18.3 \mathrm{~km})$ ASL is considered the high-altitude segment of the mission. This altitude is used operationally by the regulatory agencies as a reference for when the balloon was safely above air traffic since it represents the upper boundary of airspace in which the cruise portion of long-distance airline flights is conducted [10]. FLOAT-2 operated above $60,000 \mathrm{ft}$ for 48 minutes, representing $33.1 \%$ of the overall flight time, and received 954 ADS-B transmissions, or $46.0 \%$ of the total messages. During the high-altitude segment, the range of altitudes reported by detected aircraft ranged from 525 to $40,000 \mathrm{ft}$ ASL. These aircraft included passenger and cargo airlines, as well as private aircraft. Aircraft types included a variety of models from the three largest commercial aircraft manufacturers, suggesting that the results are not limited by hardware model 
TABle 1: Summary of the FLOAT-2 mission data. Several long-range detections were made early in the flight $(299 \mathrm{~km}$ to $528 \mathrm{~km})$ with the transmitting aircraft between 0.25 and $0.63^{\circ}$ above the horizon. Given the potential for signals passing this close to the horizon to be obstructed or refracted, it is possible that these signals did not propagate by line of sight.

\begin{tabular}{lcc}
\hline Parameter & Total mission & Above 60,000 feet \\
\hline Duration & 145 Minutes & $48 \mathrm{Minutes}$ \\
Balloon drift distance & $90.4 \mathrm{~km}$ & $7.1 \mathrm{~km}$ \\
ADS-B messages & 2,076 & 954 \\
Distinct aircraft detected & 41 & 18 \\
Aircraft types & 11 & 9 \\
Source power & $75 \mathrm{~W}$ to $500 \mathrm{~W}$ & $75 \mathrm{~W}$ to $500 \mathrm{~W}$ \\
Maximum vertical range & $85,000 \mathrm{ft}$ & $85,000 \mathrm{ft}$ \\
Maximum horizontal range & $528 \mathrm{~km}$ & $240 \mathrm{~km}$ \\
Reliable detection range & $200 \mathrm{~km}$ & $200 \mathrm{~km}$ \\
\hline
\end{tabular}

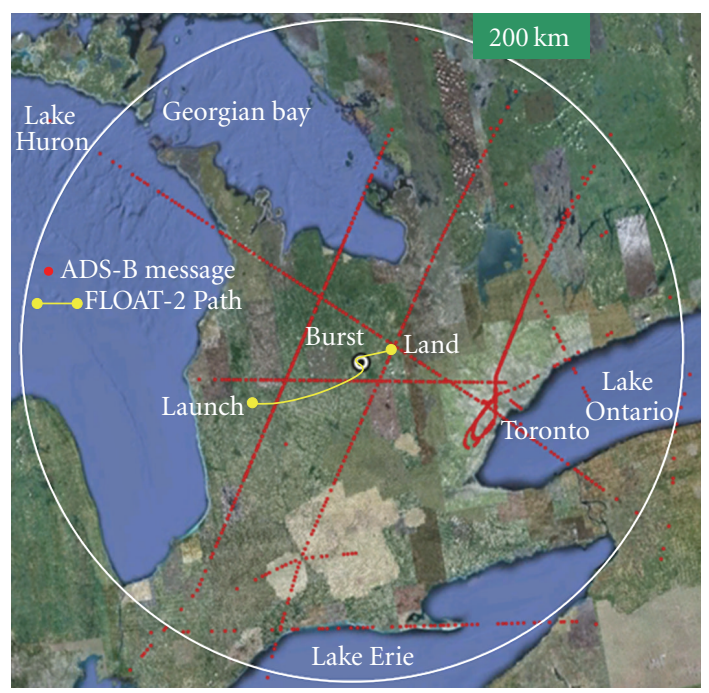

FIgUre 4: Plot of ADS-B signals received by FLOAT-2 while above $60,000 \mathrm{ft}$ ASL. Each red dot represents an ADS-B transmission. The $200 \mathrm{~km}$ range circle is centered on the burst position of the balloon.

or transmitter type. Figure 4 shows a plot of ADS-B messages received by FLOAT-2 within a $200 \mathrm{~km}$ radius during the highaltitude segment of the mission.

While a count of the number of messages and aircraft detected by the system is of interest, a key question in rating the performance of an air traffic surveillance system is whether it succeeds in detecting all of the aircraft in its field of view. Complete knowledge of the aircraft population present in a parcel of airspace, and their positions, is essential for ATS to ensure safe separation of all aircraft. An ADS$B$ sensor such as that carried on FLOAT can only detect aircraft that are transmitting ADS-B messages, so the relevant question for this experiment is whether FLOAT-2 was able to detect all ADS-B-equipped aircraft that were present, and over what area. Following the experiment, Nav Canada provided a listing of all aircraft that operated in the vicinity of the balloon flight registered as having certified ADS-B equipment onboard [11]. Numerous aircraft operate with noncertified ADS-B equipment, which broadcast position messages but are not yet certified, and thus could not be used as truth data for the experiment.

An overall assessment of the FLOAT-2 data demonstrated a reliable detection range of $200 \mathrm{~km}$ with the commercial ADS-B receiver. Contacts beyond this range were intermittent. Correlation of the list of known ADS-B equipped in the test region allowed the identification of three aircraft that were operating within $200 \mathrm{~km}$ of FLOAT-2 during the experiment period. All three of these aircraft were detected. In addition to aircraft with certified ADS-B transmitters, 38 other aircraft with uncertified ADS-B equipment were detected and tracked over horizontal ranges of up to $528 \mathrm{~km}$. Vertical detection ranges of up to $85,000 \mathrm{ft}(25.9 \mathrm{~km})$ were achieved. Table 1 gives a summary of the FLOAT- 2 mission.

Although the performance of FLOAT was promising, the dataset remains small with only three verifiable ADS$B$ equipped aircraft. A larger collection of data would be necessary to extend the appraisal of FLOAT's performance. Secondly, a key variable in the detection range has not been taken into account. The standards for ADS-B allow aircraft to transmit the signals at a range between 75 and $500 \mathrm{~W}$. Such a variation in transmitter power will greatly affect the detection range for a given receiver. Further refinement of the determination of FLOAT's performance would require greater knowledge of the actual aircraft population present during the experiment, particularly with regard to ADS$B$ equipage and transmitter power. A relatively inexpensive nanosatellite could potentially provide more meaningful data and lead the way to an operational ADS-B constellation.

\section{Future Work}

To date, no satellites have yet been launched to test the possibility of receiving ADS-B signals from space. The FLOAT high-altitude balloon mission is the first step in the development of a space-based ADS-B system. Theoretical calculations of the ADS-B signal, taking into account signal strength as well as atmospheric and ionospheric affects, demonstrate that ADS-B signals can be detected from space [12]. Assuming a link margin of $10 \mathrm{~dB}$ and a $500 \mathrm{~W}$ transmitting source, it is concluded that ADS-B signals can be detected from low Earth orbit (400 to 1,200 km altitude) 
with a receiving antenna gain of 0 to $5 \mathrm{~dB}[12,13]$. At an altitude of $800 \mathrm{~km}$, the ADS-B receiver would have a potential detection radius of 2,100 km [12]. Work is currently underway at RMCC to design and build a $3 \mathrm{U}$ nanosatellite $(10 \times 10 \times 30 \mathrm{~cm},<4 \mathrm{~kg})$ to demonstrate that ADS-B signals can be received from orbit. The commercial ADS-B detector used in FLOAT will be replaced with one specifically designed for space operations, utilizing a more advanced antenna, and employing algorithms to handle potential signal collisions due to the increased area of detection. FLOAT-3 is planned for November 2011 to test the satellite payload.

The future of air traffic control is ADS-B. A constellation of ADS-B satellite receivers could potentially allow precision tracking of aircraft around the globe, enhancing flight safety while reducing carbon emissions due to decreased fuel consumption. The FLOAT mission demonstrated that ADS$B$ signals can be reliably detected from the stratosphere and has paved the way to a spaceborne concept.

\section{Acknowledgments}

The authors would like to thank Defence Research and Development Canada, Ottawa and the Canadian Forces Directorate Space Development for financially supporting the FLOAT project [14].

\section{References}

[1] ICAO ADS-B, "Report of the ADS-B study and implementation task force meeting," Tech. Rep., International Civil Aviation Organization, Brisbane, Australia, http://www.icao.int/ icao/en/ro/apac/adsb_2003/ADSB-Report.pdf, 2003.

[2] G. Wright, "Nav Canada implements ADS-B," in Proceedings of the 9th Integrated Communications, Navigation, and Surveillance Conference, Arlington, Virginia, USA, May 2009.

[3] Nav Canada, "Hudson bay ADS-B implementation," http:// www.navcanada.ca/ContentDefinitionFiles/Services/ANSPrograms/ADS-B/ADS_B_Brochure_EN.pdf, 2008.

[4] PSC ADS-B-NRA, "Preliminary safety case for enhanced air traffic services in non-radar areas using ADS-B surveillance," Tech. Rep., European Organisation for the Safety of Air Navigation (EUROCONTROL), 2008.

[5] FAA Strategic Plan Workgroup, "Implementing the FAA ADSB link decision: a near term strategic plan,” Tech. Rep., Federal Aviation Administration, http://www.faa.gov/about/office_org/headquarters_offices/ato/service_units/enroute_broad cast/wsa/media/Implementing\%20the\%20Link\%20Decision .pdf, 2008.

[6] DO-260B, "Minimum operational performance standards for $1090 \mathrm{MHz}$ extended squitter automatic dependent surveillance-broadcast (ADS-B) and traffic information servicesbroadcast (TIS-B)," Tech. Rep., RTCA, 2009.

[7] TC AIM, "Aeronautical information manual," Tech. Rep. TP 14371E, Transport Canada, version 2009-2, effective 0901Z, 2009.

[8] P. E. Lydolph, The Climate of the Earth, Rowman \& Littlefield Publishers, 1985.

[9] FLOAT-RP-RMC-0001, "Flying laboratory for observation of ADS-B transmissions,” Tech. Rep., RMCC, 2009.
[10] Nav Canada, "Canadian NOTAM procedures manual," http:// www.navcanada.ca/NavCanada.asp?Language $=e n \&$ Content $=$ ContentDefinitionFiles/Publications/AeronauticalInfoProducts/NOTAMProcedure/default.xml, 2007.

[11] C. Burridge, “Nav Canada," Private Communications, 2009.

[12] R. Francis, Detection of automatic dependent surveillancebroadcast signals using stratospheric and orbital platforms, M.S.C. thesis, RMCC, 2009.

[13] R. Francis, J. Noël, and R. Vincent, "Orbital monitoring of automatic dependent surveillance-broadcast (ADS-B) signals for improved air traffic surveillance in remote and oceanic airspace," in Proceedings of the 62nd International Astronautical Congress, University of Western Ontario, Cape Town, South Africa, 2011.

[14] DRDC, "CIMON mission concept \& enabling technologies development study statement of work," DRDC, Ottawa. Release 3.0, DRDC File: 15EA/08-SOW-0002, 2008. 

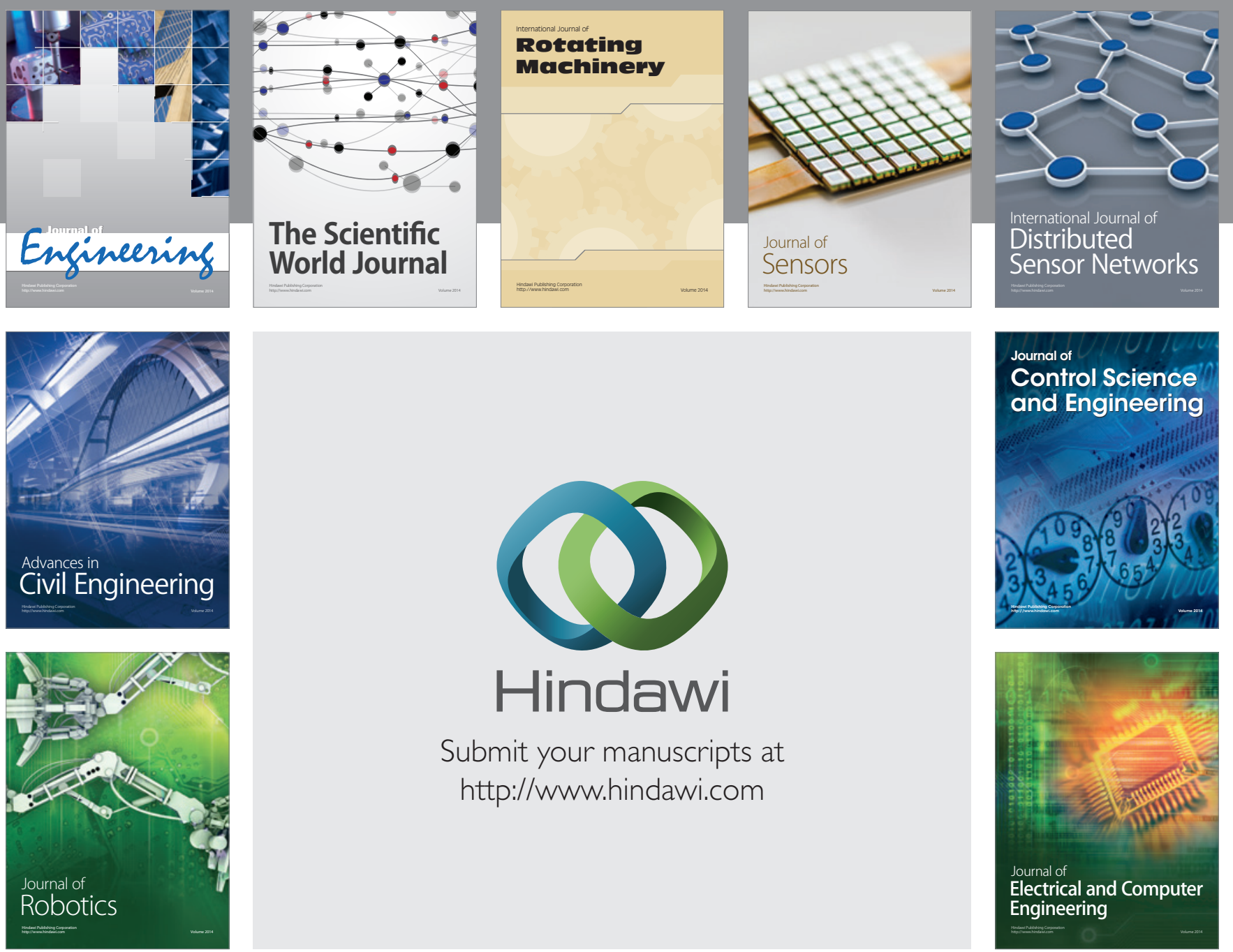

Submit your manuscripts at

http://www.hindawi.com
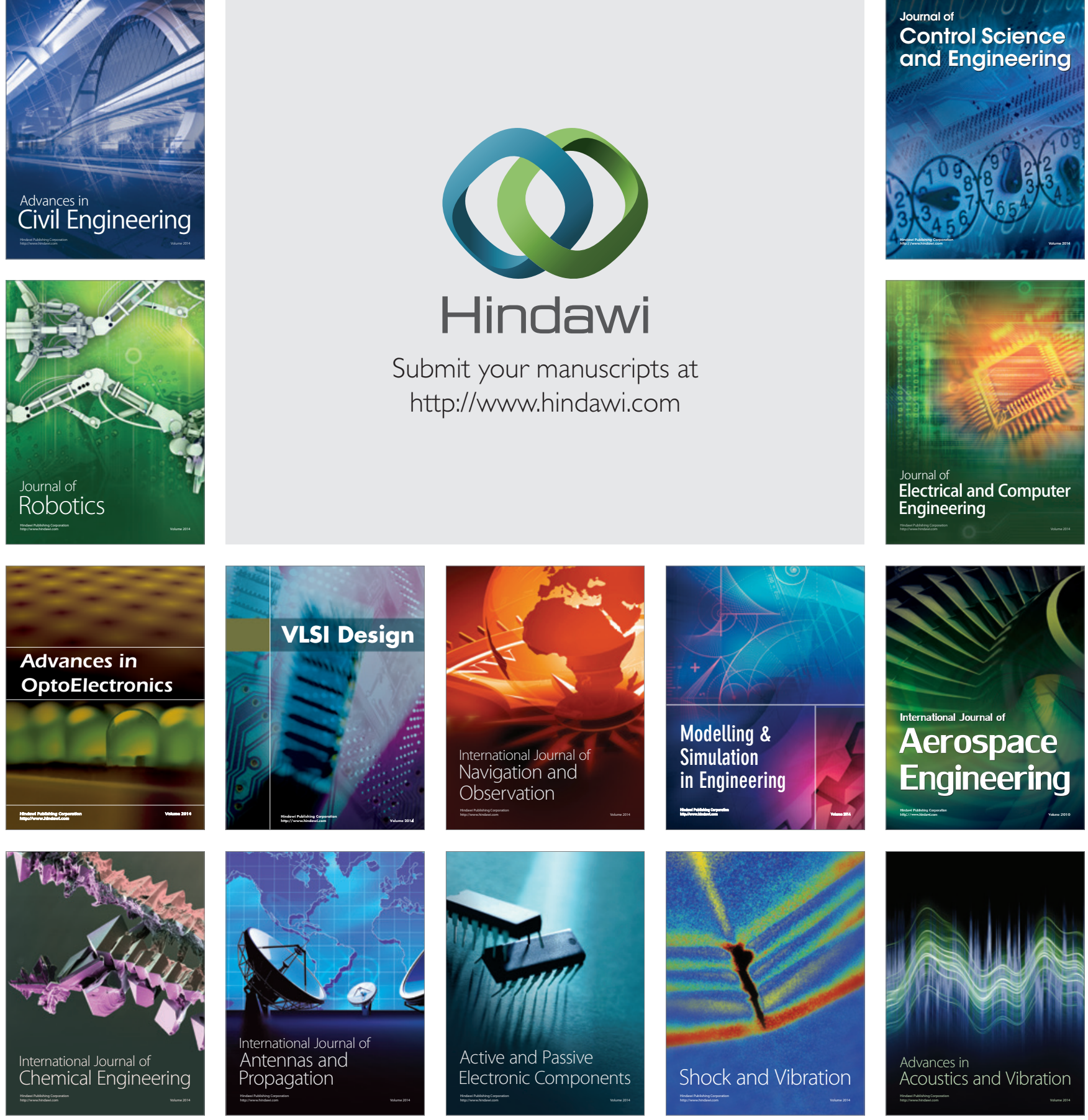